\title{
BARRIERS IN GREEN SUPPLY CHAIN MANAGEMENT: AN INDIAN FOUNDRY PERSPECTIVE
}

\author{
Balaji $\mathbf{M}^{\mathbf{1}}$, V.Velmurugan ${ }^{2}$, Manikanda Prasath $\mathrm{K}^{\mathbf{3}}$ \\ ${ }^{I}$ Senior grade Assistant professor, Department of Mechanical Engineering, Kumaraguru College of Technology, \\ Coimbatore 641 049, India \\ ${ }^{2}$ Principal, Sree Sakthi Engineering college, Karamadai, Coimbatore 641 104, India \\ ${ }^{3}$ PG Industrial engineering Scholar, Kumaraguru College of Technology, Coimbatore 641049, India
}

\begin{abstract}
At present, industries face remarkable pressure from customer's environmental awareness, stricter environmental regulations and in integrating the ethical and environmental concerns from all dimensions of managing a traditional supply chain. Green supply chain management (GSCM) is a familiar and a proven concept in injecting ethical and environmental considerations in traditional supply chains which aims in satisfying the needs of environmental policies and ultimately customers. GSCM barriers are identified through extensive literature review and expert opinion from industry professionals. The barriers stated attempt the adoption of GSC practices in foundry sector which draws immediate attention. The nature of the identified barriers is complex and interdependent which demands the application of a structural model like Interpretive Structural Modeling (ISM) technique. Driver and dependence power analysis (DDPA) is used to identify and classify the critical barriers, which have to be gradually elicited on priority basis for creating a greener platform in foundries.
\end{abstract}

Keywords: Green supply chain management, Interpretive structural modeling, Driver dependence power analysis

\section{INTRODUCTION}

Foundries worldwide have shown a growing concern for the environment over the last few decades due to pressures from environmental regulations, customers and competition in the market. In this regard there is growing awareness of customers in India and the world about environmental safeguards, need of better concepts to protect the environment form pollution and reduce consumption of the earth's depleting resources in protecting the environment for future. Green management is a promising avenue for industries to achieve a pollution and hazard-free environment. Globally, India is ranked among the top ten and is one of the biggest manufacturing economies. Green Supply Chain Management (GSCM) is slowly emerging as an important manufacturing philosophy to reduce environmental risks [8]. GSCM is the process of using environmentally friendly supply chain inputs and transforming these inputs into outputs that can be reclaimed and reused at the end of their life cycles, thus creating a sustainable supply chain. A clear understanding of the barrier of GSCM is mandatory for foundries to prioritize and better manage their resources in an efficient and effective manner. A Green Supply Chain aims at confining the wastes and also recognizes the disproportionate environmental impact of the supply chain processes within the industrial system, hence helps to conserve the energy and prevent the dissipation of dangerous material into the environment [4]. GSCM relates to a wide-range of production from product design to recycle or destroy, or from cradle to grave. The Indian Metal Casting (Foundry Industry) is well established \& producing estimated 9.99 Million MT of various grades of Castings as per International standards [3] but off late suffers within the clutches of adopting green supply chin practices. Coimbatore in south India is one among the major foundry hubs in the country involved in the making castings for several industries of which many of these are SMEs. Our research work is to identify common barriers in implementing green practices in typical Indian foundries with concentrated interests in creating GSCs for future.

\section{LITERATURE REVIEW}

Ashiskumar Bhateja, et al. (2011) [1] discuss the various activities of the Supply Chain processes of the various Indian Manufacturing Industries involving both SMEs \& Large Scale Industries to find their level of eco-friendliness. These work identifies the percentage of the green factor involved in their supply chain activities right from the procurement of the raw material to the transportation of the final product. The major external factors affecting GSCM practices adopted by the pharmaceutical companies were studied by Pandya Amit R. \& Mavani Pratik M. 2012 [2].This study aims to recognize and select appropriate strategy for implementing GSCM in an Indian pharmacy industry. ISM has been utilized to evaluate the barriers of GSCM in an automobile industry in an India by Luthra et al. (2011) [5]. Sreejith Balasubramanian et. al [6] has identified 32 barriers among economic, environmental, 
technological, social and cultural aspects for the adoption of GSCM in the UAE construction sector. In his attempt a scientific hierarchical modeling of barriers and their interrelationship has been framed and a comprehensive classification of barriers has been attempted to understand their criticality in decision making. Kshitij Dashore et al. [4] have identified various barriers and drivers of GSCM based upon the green supply management (GSM) literature and on consultations with academic experts. Their work focuses on identifying drivers and removing barriers in successful implementation of GSCM in any organization. K. Mathiyazhagan et al [7] in their study identify which barrier acts the most dominant for the adoption of green supply chain management in an Indian auto component manufacturing industry. They have deployed ISM and their results are helpful for SME in adopting green concepts in their supply chains. A model has been developed from ISM methodology were market competition, market uncertainty, lack of implementing green practices, cost implications and unawareness of customers have been identified as top level barriers. Considering the historical background, very limited trials have been attempted on achieving GSC practices in foundries which influenced our focus on the Indian foundries and its existing gap on green practices.

\section{METHODOLOGY}

The ISM methodology starts with the formulation of SSIM, an interactive learning process developed for green supply chain barriers, which indicate pair wise relationships among barriers of the foundry industry under consideration. In SSIM, the barriers of GSCM are identified based upon the GSM literature. The SSIM is then converted into a binary matrix called RM after which the Reachability set (RS) and the Antecedent Set (AS) are extracted for level partitioning. The RS consists of the barrier itself and the others which it may help to achieve whereas the AS consists of the barrier itself and the other barriers which may help to achieve it. Intersection set of RS and AS is obtained for all the barriers. The barrier for which the RS and intersection set are the same is ranked and placed at the top most level in the hierarchical structure and the ISM model is formed. The ranked barriers are subsequently discarded and the iteration is continued to find the level of each barrier in the hierarchy.

The graph theoretical approach (GTA) is used for identification of barriers and generation of Directed graph (Diagraph) from the final RM by vertices and edges. The relationships between the barriers are represented by an arrow in the diagraph. In the digraph, the top level barrier are obtained from level partitioning and are positioned at the top and subsequent levels are placed till the bottom level is placed at the lowest position. Driver dependence power analysis (DDPA) is used to classify barriers into four zones namely autonomous barriers, dependent barriers, linkage barriers and driver barriers. The first zone namely autonomous barriers have weak driving power and dependence and are thus disconnected from the system. The second zone namely dependent barriers denote barriers with weak driving power and strong dependence power. The third zone namely linkage barriers denotes barriers with strong driving power and strong dependence power. The fourth zone namely driver barriers denote barriers with strong driving power and weak dependence power. The graph between dependence power and driver power is drawn and analyzed with deeper interests in the driver quadrant which showcase critical barrier in adopting GSM practices.

\section{GREEN SUPPLY CHAIN BARRIER}

Adopting GSCM in foundries simply underline the need to remove barriers. The objective of this work is to identify the dominant barrier among the recommended barriers from literature survey and investigate the imperative and mutual relationship of the 10 ultimate barriers for the implementation of GSCM in foundries in Coimbatore, South India. Green Barriers are those which if addressed lift the organization's green agility levels and influence each other. Careful readings on the previous works have given the confined list of GSC barriers as shown in table 1.

Table -1: Green Supply Chain barrier

\begin{tabular}{|l|l|l|l|}
\hline SI No & Barrier of GSCM & Description & Source \\
\hline 1. & $\begin{array}{l}\text { Lack of Government } \\
\text { regulation and legislation }\end{array}$ & Providing reward for best green follower. & Walker et al. (2008)[9] \\
\hline 2 & $\begin{array}{l}\text { Lack of knowledge and } \\
\text { experience }\end{array}$ & $\begin{array}{l}\text { Lack of knowledge in GSCM among the } \\
\text { supply chain stakeholders } \\
\text { Lack of experience among the stakeholders in } \\
\text { executing GSCM } \\
\text { Feeling of 'too complex' to implement GSCM } \\
\text { among stakeholders }\end{array}$ & $\begin{array}{l}\text { Sreejith } \\
\text { (2012) [6] }\end{array}$ \\
\hline
\end{tabular}




\begin{tabular}{|c|c|c|c|}
\hline 3 & $\begin{array}{l}\text { Cost of implementation } \\
\text { for GSCM }\end{array}$ & $\begin{array}{l}\text { Reflects to the high initial cost investment } \\
\text { required to implement various green } \\
\text { methodologies such as green design, green } \\
\text { manufacturing, green labeling of packing etc }\end{array}$ & Mudgal et al. (2009); [15] \\
\hline 4 & $\begin{array}{l}\text { Lack of acceptance of } \\
\text { advancement in new } \\
\text { technology }\end{array}$ & $\begin{array}{l}\text { Emphasizes on adoption of various } \\
\text { advancement in technology to the older } \\
\text { established technology in existing organization. }\end{array}$ & $\begin{array}{l}\text { Daine Holt and Abby } \\
\text { Ghobadian (2009). [10] }\end{array}$ \\
\hline 5 & $\begin{array}{l}\text { Lack of top level } \\
\text { management commitment }\end{array}$ & $\begin{array}{l}\text { Resistant of top level management towards } \\
\text { implementation of green practices. }\end{array}$ & $\begin{array}{l}\text { Rao and Holt (2005), Holt and } \\
\text { Ghobadian (2009), [11] [12] }\end{array}$ \\
\hline 6 & $\begin{array}{l}\text { Lack of understanding } \\
\text { among supply chain } \\
\text { stakeholders }\end{array}$ & $\begin{array}{l}\text { Lack of cooperation within the supply chain } \\
\text { Stakeholders } \\
\text { Lack of communication and information } \\
\text { sharing among supply chain stakeholders }\end{array}$ & $\begin{array}{ll}\text { Sreejith } & \text { Balasubramanian } \\
(2012)[6] & \end{array}$ \\
\hline 7 & $\begin{array}{l}\text { Lack of management } \\
\text { initiatives for transport } \\
\text { and logistics }\end{array}$ & $\begin{array}{l}\text { Poor managerial management involves in } \\
\text { logistics in the organization. }\end{array}$ & M.D. Singh (2008) [14] \\
\hline 8 & $\begin{array}{l}\text { Market Competition and } \\
\text { Uncertainty }\end{array}$ & $\begin{array}{l}\text { It enables new innovations in production and } \\
\text { operation methodologies, confining wastes and } \\
\text { reduces energy usages. }\end{array}$ & Yu Lin (2007) [16] \\
\hline 9 & Financial implications & $\begin{array}{l}\text { High initial investment in implementing } \\
\text { GSCM, Slow return on Investments(ROI) after } \\
\text { implementing GSCM }\end{array}$ & $\begin{array}{ll}\text { Sreejith } & \text { Balasubramanian } \\
(2012)[6] & \end{array}$ \\
\hline 10 & Lack of training in GSCM & $\begin{array}{l}\text { Reflects lack of training given to the employee } \\
\text { of the organization resisting enhancement of } \\
\text { overall performance of supply chain and green } \\
\text { practices in it. }\end{array}$ & $\begin{array}{l}\text { Yu Lin, C., and Hui Ho, Y. } \\
\text { (2008) [13] }\end{array}$ \\
\hline
\end{tabular}

\section{INTERPRETIVE STRUCTURAL MODELING}

\section{(ISM)}

Interpretive Structural Modeling is used to analyze the complex socioeconomic systems. ISM is an interactive learning process in which a set of different and directly related elements are structured into a comprehensive systematic model. The basic idea of ISM is to decompose a complicated system into several subsystems. ISM starts with identification of barriers, which are relevant to the problem, and then extends with a group problem solving technique. Then a contextually relevant subordinate relation is chosen and a structural self-interaction matrix (SSIM) is developed based on pairwise comparison of barriers. In the next step, the SSIM is converted into a reachability matrix (RM) followed by a digraph. Finally based on the partitioning of the elements, a matrix model is developed.

\subsection{Formation of Structural Self Interaction Matrix (SSIM)}

Group of experts, from the foundry were consulted in identifying the nature of contextual relationships among the barrier as shown in table 2 . In analyzing the direction of relationship between the green barrier for developing SSIM, following four symbols have been used:

$\mathrm{V}$ - Enabler i will help to achieve enabler j;

A - Enabler $\mathrm{j}$ will help to achieve Enabler i;

$\mathrm{X}$ - Enabler $\mathrm{i}$ and $\mathrm{j}$ will help to achieve each other; and

$\mathrm{O}-$ Enablers $\mathrm{i}$ and $\mathrm{j}$ are unrelated

Table-2: Formation of SSIM Matrix

\begin{tabular}{|l|l|l|l|l|l|l|l|l|l|l|}
\hline S1. No. No. & BARRIERS & $\mathbf{1 0}$ & $\mathbf{9}$ & $\mathbf{8}$ & $\mathbf{7}$ & $\mathbf{6}$ & $\mathbf{5}$ & $\mathbf{4}$ & $\mathbf{3}$ & $\mathbf{2}$ \\
\hline 1 & Lack of Government regulation and legislation & $\mathrm{X}$ & $\mathrm{X}$ & $\mathrm{V}$ & $\mathrm{V}$ & $\mathrm{V}$ & $\mathrm{V}$ & $\mathrm{V}$ & $\mathrm{O}$ & $\mathrm{V}$ \\
\hline 2 & $\begin{array}{l}\text { Lack of knowledge and } \\
\text { experience }\end{array}$ & $\mathrm{V}$ & $\mathrm{X}$ & $\mathrm{O}$ & $\mathrm{O}$ & $\mathrm{V}$ & $\mathrm{V}$ & $\mathrm{X}$ & $\mathrm{V}$ & \\
\hline 3 & Cost of implementation for GSCM & V & A & A & X & O & O & V & & \\
\hline
\end{tabular}




\begin{tabular}{|l|l|l|l|l|l|l|l|l|l|l|}
\hline 4 & Lack of acceptance of advancement in new technology & A & A & A & O & X & X & & & \\
\hline 5 & Lack of top level management commitment & O & V & X & O & X & & & & \\
\hline 6 & Lack of understanding among supply chainstakeholders & & & & & & & & & \\
& & V & V & V & V & & & & \\
\hline 7 & Lack of management initiatives for transport and logistics & X & A & A & & & & & & \\
\hline 8 & Market Competition and Uncertainty & O & A & & & & & & & \\
\hline 9 & Financial implications & X & & & & & & & \\
\hline 10 & Lack of training in GSCM & & & & & & & & & \\
\hline
\end{tabular}

\subsection{Reachability Matrix}

From the deduced SSIM, the RM can be constructed from alpha variables tabulated with the binary numbers. Summing up rows and columns renders a methodology to calculate the driver and dependence values of corresponding barriers. As shown in table 3 , the SSIM is converted into a binary matrix called the reachability matrix by substituting 1 and 0 on behalf of $\mathrm{V}, \mathrm{A}, \mathrm{X}, \mathrm{O}$ based on the following rules.

- If the (i, j) entry in the SSIM is $V$, then the (i, j) entry in the reachability matrix becomes 1 and the $(j, i)$ entry becomes 0 .

- If the (i,j) entry in the SSIM is A, then the (i,j) entry in the reachability matrix becomes 0 and the $(j, i)$ entry becomes 1 .

- If the $(i, j)$ entry in the SSIM is $X$, then the $(i, j)$ entry in the reachability matrix becomes 1 and the $(j, i)$ entry also becomes 1 .

- If the (i,j) entry in the SSIM is $O$, then the $(i, j)$ entry in the reachability matrix becomes 0 and the $(j, i)$ entry also becomes 0 .

From the reachability matrix, the driver power of each element is obtained by the summation of 1 's in the corresponding row and dependence power of each element is obtained by the summation of 1's in the corresponding column.

Table -3: Reachability Matrix

\begin{tabular}{|c|c|c|c|c|c|c|c|c|c|c|c|c|}
\hline Sl.No. & Barriers & 1 & 2 & 3 & 4 & 5 & 6 & 7 & 8 & 9 & 10 & $\in$ Driver \\
\hline 1 & Lack of Government regulation and legislation & 1 & 1 & 0 & 1 & 1 & 1 & 1 & 1 & 0 & 1 & 8 \\
\hline 2 & Lack of knowledge and experience & 0 & 1 & 1 & 1 & 1 & 1 & 0 & 0 & 0 & 1 & 6 \\
\hline 3 & Cost of implementation for GSCM & 0 & 0 & 1 & 1 & 0 & 0 & 1 & 0 & 0 & 1 & 4 \\
\hline 4 & Lack of acceptance of advancement in new technology & 0 & 1 & 0 & 1 & 1 & 1 & 0 & 0 & 0 & 0 & 4 \\
\hline 5 & Lack of top level management commitment & 0 & 0 & 0 & 1 & 1 & 1 & 0 & 1 & 1 & 0 & 5 \\
\hline 6 & Lack of understanding among supply chain stakeholders & 0 & 0 & 0 & 1 & 1 & 1 & 1 & 1 & 1 & 1 & 7 \\
\hline 7 & Lack of management initiatives for transport and logistics & 0 & 0 & 1 & 0 & 0 & 0 & 1 & 0 & 0 & 1 & 3 \\
\hline 8 & Market Competition and Uncertainty & 0 & 0 & 1 & 1 & 1 & 0 & 1 & 1 & 0 & 0 & 5 \\
\hline 9 & Financial implications & 0 & 0 & 1 & 1 & 0 & 0 & 1 & 1 & 1 & 1 & 6 \\
\hline 10 & Lack of training in GSCM & 1 & 0 & 0 & 1 & 0 & 0 & 1 & 0 & 1 & 1 & 5 \\
\hline & $\in$ Dependence & 2 & 3 & 5 & 9 & 6 & & 7 & 5 & 4 & 7 & \\
\hline
\end{tabular}




\subsection{Level Partitioning and ISM Model Formulation}

From the final reachability matrix the reachability set, the antecedent set and the intersection sets for each barrier are found. The barriers for whom the reachability and the intersection sets are the same occupy the top-level in the ISM hierarchy as they will not augment any other element above their level. Once the top-level element is identified, it is separated from the others and the process is repeated to find out the elements in the next level. This process is continued until the level of each element is found as shown in table 4 and table 5. From level partitioning, the ISM model is generated as shown in Fig. 1 which exhibits the relationship between the barriers $i$ and $j$.

\subsection{Classification of Green Supply Chain Barriers}

Based on the findings of driver dependence power, the barriers were grouped into four clusters as depicted in Fig. 2. Each element is plotted as a point using the conventional $x-y$ coordinate system [18] [19] and identified as Dependent barriers, Driver barriers, Autonomous barriers and Linkage barriers. It is assumed that by boosting driver barriers, the other barriers get self driven [9] and thus driver barriers are targeted first.

Table -4: Level Partitioning - Iteration 1

\begin{tabular}{|l|l|l|l|l|}
\hline & & Antecedent & $\begin{array}{l}\text { Intersect } \\
\text { ion Set }\end{array}$ & \\
\hline & Ret & & \\
\hline 1 & $1,2,4,5,6,7,8,10$ & 1,10 & 1,10 & \\
\hline 3 & $2,3,4,5,6,10$ & $1,2,4$ & 2,4 & \\
\hline 4 & $3,4,7,10$ & $2,3,7,8,9$ & 3,7 & \\
\hline 5 & $2,4,5,6$, & $1,2,3,4,5,6,8,9$ & $2,4,5,6$ & \\
\hline 6 & $4,5,6,8,9$ & 10 & & I \\
\hline 7 & $3,6,7,8,9,10$ & $1,2,4,5,6$ & $4,5,6$ & \\
\hline 8 & $3,4,5,7,8$ & $1,3,6,7,8,9$, & $3,6,8$ & \\
\hline 9 & $3,4,7,8,9,10$ & 10 & $3,5,6,8$ & \\
\hline 10 & $1,4,7,9,10$ & $1,5,6,8,9$ & 5,8 & \\
\hline
\end{tabular}

Table -5: Level Partitioning - Iteration 2-5

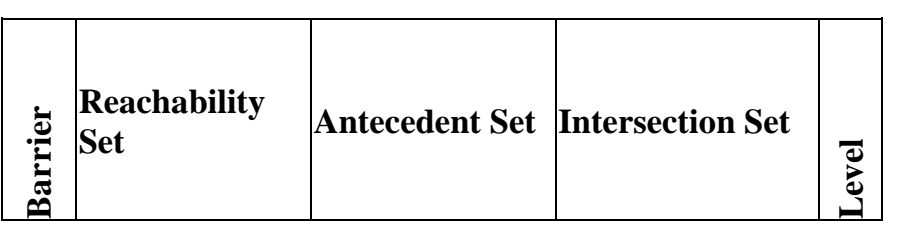

\begin{tabular}{|l|l|l|l|l|}
\hline 1 & $1,7,8,10$ & 1,10 & 1,10 & V \\
\hline 2 & 3,10 & $1,2,4$ & 2,4 & V \\
\hline 3 & $3,7,10$ & $2,3,7,8,9$ & 3,7 & V \\
\hline 5 & 8,9 & $1,2,4,5,6,8$ & $4,5,6,8$ & IV \\
\hline 6 & $7,8,9,10$ & $1,2,4,5,6$ & $4,5,6$ & V \\
\hline 8 & $3,7,8$ & $1,5,6,8,9$ & 5,8 & III \\
\hline 9 & $3,7,8,9,10$ & $5,6,9,10$ & 9,10 & V \\
\hline 10 & $1,7,9,10$ & $1,2,3,6,7,9,10$ & $1,7,9,10$ & II \\
\hline
\end{tabular}

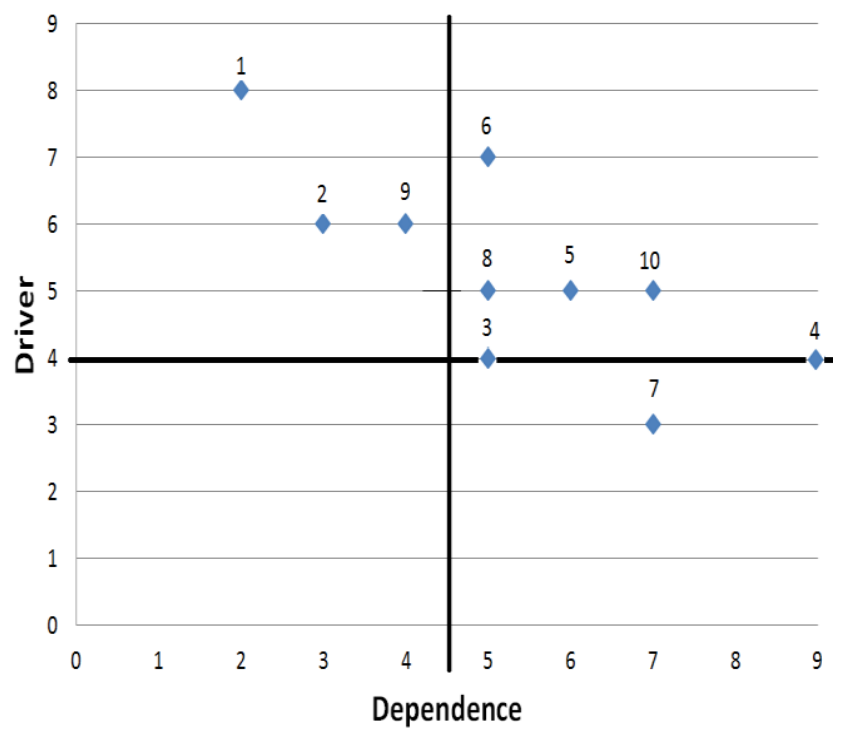

Fig -2: Classification of Barriers

\section{RESULTS \& DISCUSSIONS}

The proposed model provides an opportunity to understand the dynamics among the green supply chain barriers in a foundry. ISM develops a hierarchy of green supply chain barriers, so that managers can prioritize the important barriers which in turn would influence other barriers. The work classifies the barriers as autonomous, dependent, linkage and driver categories and gives a clear picture of the complicated system. The notable point that draws attention is that Driver barriers 1, 2 \& 9 namely Lack of Government regulation and legislation, lack of knowledge and experience and financial implications are those which have to be addressed immediately from the viewpoint of adopting successful GSCM practices with respect to the foundry under limelight. 


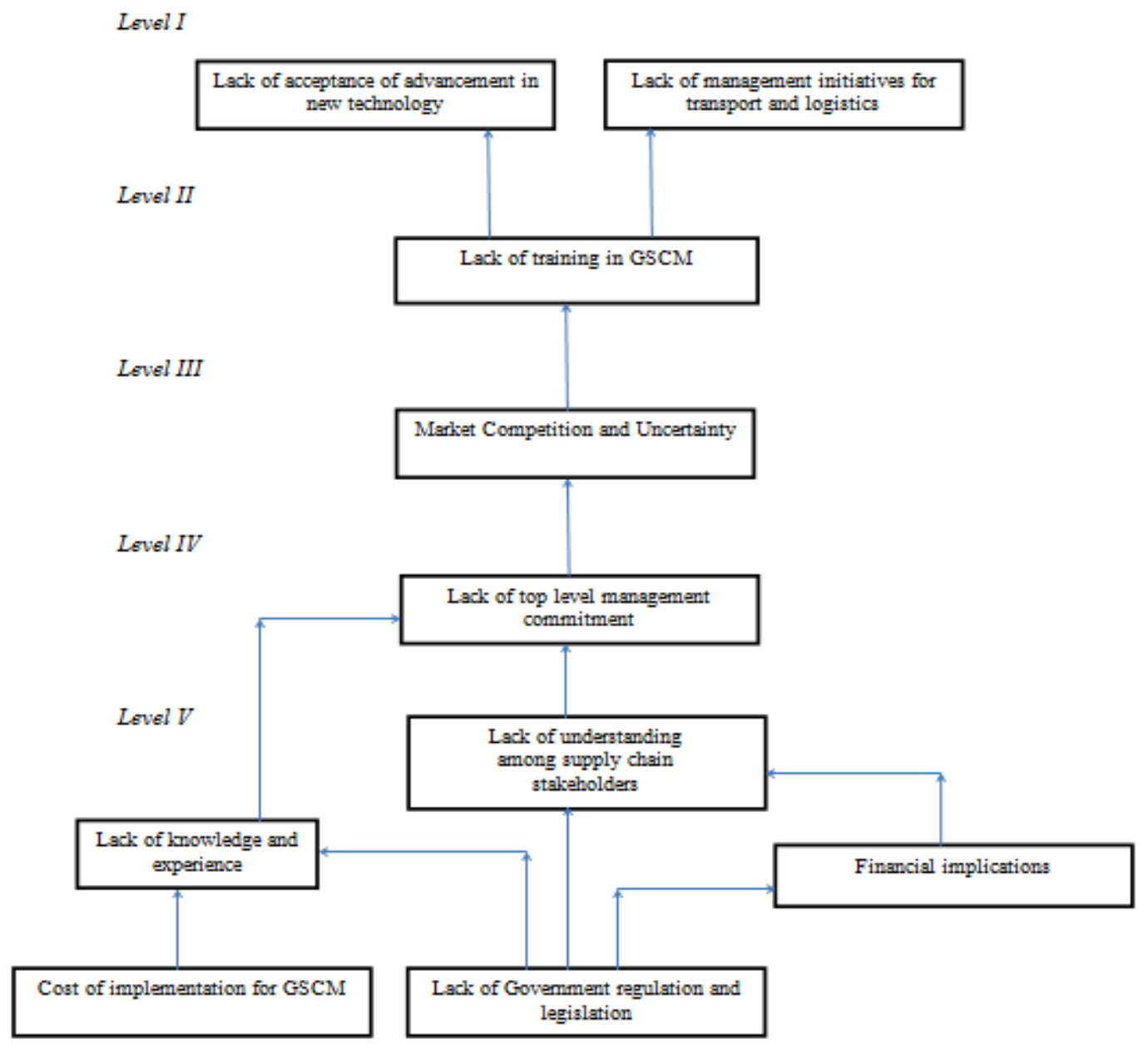

Fig -1: ISM Model

\section{CONCLUSIONS}

The environmental consciousness of customers and the increase of environmental image in the market day by day have coerced SME's indirectly to think about cleaner production by means of getting acquainted to GSCM practices. Foundries play an important role in a country's economy and thus should start adopting GSCM as the concurrent strategy for building their environmental image although in most countries it is still at infantry. The barriers that hinder the implementation of GSCM create considerable challenges both for the technical experts and mangers of SME's. Ten of the prevalent barriers to implement GSCM in Indian foundries have been identified and modelled. The paper has certainly thrown light on some of the critical barriers and analyzed the level of interaction among them using ISM. Developing a sound implementation and assessment tool on GSCM is critical, especially for growing economies. The research paper surfaces the agility paradigm and the required sub strategies for green foundries on a competitive edge and also given a direction for improving performance of the processes and products according to the requirements of current environmental regulations. Although our hypothetical model of analyzing barriers in practicing GSCM in Indian foundry industry is convincing, it suffers from the flaw that it is based upon experts' opinions which may lead to biased ness and that model is yet to be tested in a realistic scenario. To be precise, the barriers taken from the rich literature of the past may not suit the real world.

\section{REFERENCES}

[1]. Ashiskumar Bhateja, RajeshBabbar, Sarbjit Singh and Anish Sachdeva (2011), "Study of Green Supply Chain Management in the Indian Manufacturing Industries: A Literature Review cum an Analytical Approach for the measurement of performance", IJCEM International Journal of Computational Engineering \& Management, vol. 13, 84-99. 
[2]. PandyaAmit R, Mavani Pratik M (2012), “An empirical study of green supply chain management drivers, practices and performances: with reference to The pharmaceutical industry of ankleshwar (gujarat)"॥, I.J.E.M.S., vol. 3(3), 339-355.

[3]. B.Revathi, Dr.R.Jayachitra, S.Janaki (2013), "Empirical Study of the Green Supply Chain Management Practices in Foundry and Their Relation to the Organizational Performances", MISAA, vol.3, 1-9.

[4]. Kshitij Dashore and Dr. Nagendra Sohani (2013) "Green Supply Chain Management - Barriers \& Drivers: A Review", International Journal of Engineering Research \& Technology, vol. 2 (4), 2021-2030.

[5]. Sunil Luthra, Vinod Kumar \& Abid Haleem (2011), "Barriers to implement Green Supply Chain Management in automobile industry using Interpretive Structural Modeling (ISM) Technique - An Indian Perspective", Journal of Industrial Engineering and Management, vol. 4(2), 231-257.

[6]. Sreejith Balasubramanian (2012),“A Hierarchical Framework of Barriers to Green Supply Chain Management in the Construction Sector", Journal of Sustainable Development, vol. 5(10), 15-27.

[7]. K. Mathiyazhagan, Kannan Govindan, A. NoorulHaq and Yong Geng (2013)“An ISM approach for the barrier analysis in implementing green supply chain management", Journal of Cleaner Production, vol. 47, 283-297.

[8]. K. Mathiyazhagan, A. NoorulHaq (2013) “An ISM approach for the barrier analysis in implementing green supply chain management", Int J Adv Manuf Technol, vol. 68:817833.

[9]. Walker H, Di Sisto L and McBain D (2008) "Drivers and barriers to environmental supply chain management practices: lessons from the public and private sectors", Journal of Purchasing and Supply Management, vol. 14(1), ,69-85.

[10]. Daine Holt and Abby Ghobadian (2009) "An Empirical Study of Green Supply Chain Management Practices Amongst UK Manufacturers", Journal of Manufacturing Technology Management, vol. 20(7), 933-966.

[11]. Holt D and Ghobadian A (2009) "An empirical study of green supply chain management practices amongst UK manufacturers", Journal of Manufacturing Technology Management, vol. 20(7), 933-956.

[12]. Rao P and Holt D "Do green supply chains lead to competitiveness and economic Performance?", International Journal of Operations \& Production Management, Vol. 25(9), 2005, pp. 898-916.

[13]. Yu Lin, C., \& Hui Ho, Y. (2008) "An Empirical Study on Logistics services provider, intention to adopt Green Innovations", Journal of Technology, Management and Innovation, vol. 3(1), 17-26.

[14]. M. D. Singh and R. Kant (2008), "Knowledge management barriers: An interpretive structural modeling approach", International Journal of Management Science and Engineering Management, vol. 3, 141-150.

[15]. Mudgal, R.K., Shankar, R., Talib, P., \& Raj, T. (2009).

"Greening the supply chain practices: an Indian perspective of enablers' relationship", Int. Journal of Advanced Operations Management, vol.1, 151-176.

[16]. Yu Lin, C. (2007) "Adoption of green supply in Taiwan logistic industry”, Journal of management study, vol. 7, 90-98.

\section{BIOGRAPHIES}

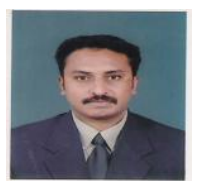

M. Balaji is a senior grade assistant professor in the Department of Mechanical engineering at Kumaraguru College of Technology, Coimbatore, India .He received his BE degree in Mechanical engineering and ME degree in industrial engineering from Bharathiar university, Coimbatore, India. He also has an MBA degree from School of distance education-Bharathiar university, Coimbatore to his credential. $\mathrm{He}$ is a life member of Indian institution of industrial engineering and institute for supply management. He has 11 years of teaching and research experience to his credit and has published more than 7 internationa/national journal papers and 10 papers in International/National conferences. He is presently focused in improving the supply chain agility of Indian firms for his doctoral programme.

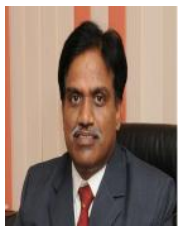

Dr. V. Vel Murugan is the Principal at Sree Sakthi Engineering College, Coimbatore, India. $\mathrm{He}$ received his $\mathrm{BE}$ degree from Government College of Engineering, Salem, India and his ME degree from Annamalai University, Annamalai Nagar, India and his $\mathrm{PhD}$ in Mechanical Engineering from Bharathiar University, Coimbatore, India. He has 22 years of teaching and research experience and supervising ten $\mathrm{PhD}$ scholars to his credential. He has published more than 15 research papers in international/national journals and presented 50 papers in international/national conferences. His potential areas of research include manufacturing and optimization.

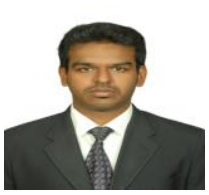

Dr. V. Vel Murugan is the Principal at Sree Sakthi Engineering College, Coimbatore, India. He received his $\mathrm{BE}$ degree from Government College of Engineering, Salem, India and his ME degree from Annamalai University, Annamalai Nagar, India and his $\mathrm{PhD}$ in Mechanical Engineering from Bharathiar University, Coimbatore, India. He has 22 years of teaching and research experience and supervising ten $\mathrm{PhD}$ scholars to his credential. He has published more than 15 research papers in international/national journals and presented 50 papers in international/national conferences. His potential areas of research include manufacturing and optimization. 